\title{
MCT4 has a potential to be used as a prognostic biomarker - a systematic review and meta-analysis
}

\author{
Arslaan Javaeed, ${ }^{1}$ Sanniya Khan Ghauri ${ }^{2}$ \\ ${ }^{1}$ Department of Pathology, Poonch Medical College, Rawalakot; ${ }^{2}$ Department of Emergency Medicine, Shifa \\ International Hospital, Islamabad, Pakistan
}

\begin{abstract}
The role of several metabolic changes, such as hypoxia and acidosis, in the tumour environment has caught the attention of researchers in cancer progression and invasion. Lactate transport is one of the acidosis-enhancing processes that are mediated via monocarboxylate transporters (MCTs). We conducted a systematic review and meta-analysis to investigate the expression of two cancer-relevant MCTs (MCT1 and MCT4) and their potential prognostic significance in patients with metastasis of different types of cancer. Studies were included if they reported the number of metastatic tissue samples expressing either low or high levels of MCT1 and/or MCT4 or those revealing the hazard ratios (HRs) of the overall survival (OS) or disease-free survival (DFS) as prognostic indicators. During the period between 2010 and 2018, a total of 20 articles including 3831 patients (56.3\% males) were identified. There was a significant association between MCT4 expression (high versus low) and lymph node metastasis [odds ratio $(\mathrm{OR})=1.87,95 \%$ confidence interval $(\mathrm{CI})=1.10-3.17$, $\mathrm{P}=0.02]$ and distant metastasis $(\mathrm{OR}=2.18,95 \% \mathrm{CI}=1.65-2.86$, $\mathrm{P}<0.001)$ and the correlation remained significant for colorectal and hepatic cancer in subgroup analysis. For survival analysis, patients with shorter OS periods exhibited a higher MCT4 expression [hazard ratio $(\mathrm{HR})=1.78,95 \% \mathrm{CI}=1.49-2.13, \mathrm{P}<0.001$ ], while DFS was shorter in patients with high MCT1 $(\mathrm{HR}=1.48$, 95\% $\mathrm{CI}=1.04-2.10, \mathrm{P}=0.03)$ and MCT4 expression $(\mathrm{HR}=1.70$, $95 \% \mathrm{CI}=1.19-2.42, \mathrm{P}=0.003)$ when compared to their counterparts
\end{abstract}

Correspondence: Arslaan Javaeed, Department of Pathology, Poonch Medical College, Rawalakot, Pakistan.

Tel.: +92.300.4717057.

E-mail: arslaanjavaeed@yahoo.com

Key words: Metastasis; lactate transporters; monocarboxylate transporters proteins; acidosis; mortality.

Contributions: the authors contributed equally.

Conflicts of interest: the authors declare no potential conflicts of interest.

Received for publication: 1 December 2018.

Accepted for publication: 27 June 2019.

This work is licensed under a Creative Commons Attribution NonCommercial 4.0 License (CC BY-NC 4.0).

${ }^{(C)}$ Copyright: the Author(s), 2019

Licensee PAGEPress, Italy

Oncology Reviews 2019; 13:403

doi:10.4081/oncol.2019.403 with low expression levels. Future research studies should consider the pharmacologic inhibition of MCT4 to effectively inhibit cancer progression to metastasis.

\section{Introduction}

The genomic revolution over the past three decades has dramatically advanced our knowledge about the molecular and metabolic mechanisms of cancer and improved several aspects in relation to understanding, diagnosing, and treating multiple primary cancers. However, the inherent features of genomic and cellular changes of malignant cells are often perplexing. The rate, timing, and sites of these evolutionary changes are unpredictable and they are seemingly dependent on the cellular genomic makeup as well as the specific pressures placed on it. ${ }^{1}$ Such advances in cancer diagnosis have led to remarkable benefits in treatment outcomes when the disease is detected early. Nevertheless, the development of a metastatic phenotype represents a real challenge and is deemed the most lethal attribute of a malignancy. Reports have revealed that metastasis contributes to approximately $90 \%$ of all cancer-related deaths. ${ }^{2,3}$ Additionally, there is a variation in patients' prognosis according to the distant organ. For instance, based on the Surveillance, Epidemiology and End Results database, breast cancer patients with bone metastasis had a favourable prognosis, while those with metastasis in the brain or multiple sites had the poorest prognosis. ${ }^{4}$ Furthermore, distant tumours are not suitable indications for surgical or radiological therapies and they are resistant to chemotherapeutic agents..$^{5}$

Metastasis is a complicated, multiphasic process in which the primary tumour cells invade the surrounding tissues due to hypermotility, intravasate into the blood circulation, disseminate to reach a capillary bud, permeate the blood vessels to reach a discontiguous organ (extravasation), and finally colonise in the distant target and form a micrometastasis through angiogenesis and proliferation, which ultimately reflects as a macroscopic tumour. ${ }^{6}$ Several molecular mechanisms have been investigated in the literature regarding initiation of cancer cell metastasis, revealing a potential involvement of genetic mutations, tumour necrosis, immune escape, promoting blood circulation, and increased rates of glycolysis. ${ }^{7}$ Actually, the latter mechanism was initially demonstrated in 1924 through the accelerated engagement of cancer cells in glycolytic cascades, even in normoxic conditions. ${ }^{8}$ Intracellular lactate should be exported out of cancer cells to avoid cellular acidosis and apoptosis. Large amounts of lactic acid are produced via glycolysis leading to increased acidity in the extracellular environment. Additionally, lactate has been identified as a remarkable source of energy in cancer. ${ }^{9}$ To this end, the role of monocarboxylate transporters (MCTs) could be critical. Fourteen members belong to the MCT family (SLC16A) and they transport pyruvate, lactate and ketone across the cell membrane. ${ }^{10}$ More specifically, 
MCT1 (encoded by the SLC16A1 gene) and MCT4 (SLC16A3) export monocarboxylates coupled with a proton and they play a regulatory role on intracellular $\mathrm{pH}$ in cells relying on high glycolysis rates, such as red blood cells, skeletal muscle cells and tumour cells. ${ }^{10,11}$ Both MCT1 and MCT4 are expressed variably in normal and malignant cells. For instance, on a specific immunoreactivity (IR) score ranging between 0 (no IR) to 4 (strong IR), Froberg et $a l .{ }^{12}$ revealed weak MCT1 IR in the microvessels and ependymocytes of normal human brain tissue, while it was strongest for highgrade glial neoplasms, astrocytoma, and glioblastoma multiforme when compared to the IR of low-grade glial neoplasms (2.8333 vs $1.0833, \mathrm{P}<0.000)$. A consistently used method in the literature to semiquantitatively evaluate IR has shown that the majority of breast tumour cells were strongly IR to MCT1 (79.2\% versus $33.3 \%$ in normal cells) and to MCT4 (95.5\% versus $46.7 \%) .{ }^{13}$ However, the knowledge linking MCT1 and MCT4 expression and metastasis, as a major life-threatening condition, is still unclear. Herein, this review has provided a systematic insight into the association between the occurrence of metastasis and the expression of both MCT1 and MCT4 in different types of cancer to further characterise the impact of their targeted inhibition as a therapeutic approach. Furthermore, the integrative role of both proteins as prognostic biomarkers for survival in patients with cancer was analysed statistically.

\section{Materials and Methods}

\section{Search strategy and study selection}

The main search strategy was designed according to the guidelines of the Preferred Reporting Items for Systematic reviews and Meta-Analyses (PRISMA). ${ }^{14}$ A comprehensive search process was conducted on the following scientific databases: PubMed, Embase, Google Scholar and Web of Science for studies published between January $1^{\text {st }}, 2010$ and November $24^{\text {th }}, 2018$. The main search was conducted in PubMed using the keywords: ("monocarboxylate transporter1" OR "MCT1") AND ("metastasis") AND ("prognosis" OR "survival" OR "predict") and ("monocarboxylate transporter4" OR "MCT4") AND ("metastasis") AND ("prognosis" OR "survival" OR "predict") and the same terms were subsequently utilised in other databases. The bibliographies of the retrieved articles were searched for additional studies for inclusion. Two independent authors performed the search process and any disagreement was resolved by discussion.

\section{Eligibility criteria}

The included studies should report their results based on the pathological examination of MCT1 and/or MCT4 in clinical cohorts and the outcomes should be categorised according to their expression levels into either low or high. Studies reporting data about the association between MCT expression and lymph node metastasis (LNM) and/or distant metastasis (DM) were considered. Additionally, given the significant association between LNM and lymphovascular invasion, ${ }^{15,16}$ the latter was deemed an indicator of LNM during data collection in relation to MCT expression. For prognostic significance, articles should provide the hazard ratios (HRs) and 95\% confidence intervals (CIs) for overall survival (OS) or disease-free survival (DFS). Studies were excluded if they provided insufficient data to be extracted. In addition, review articles, case reports, cell culture-based studies, preclinical experiments, case reports, non-English articles and systematic reviews were not eligible for inclusion.

\section{Data extraction}

The following data were extracted for each individually included study: author name(s), date of publication, the type of primary cancer, the investigated MCT(s), number of patients, number of patients with metastasis along with exhibiting high or low expression levels, and the total number of patients in each group. Data relevant to metastasis to lymph nodes or distant organs and tissues were also extracted. Furthermore, HRs and their corresponding minimum and maximum $95 \%$ CIs were also collected, including the methods by which they were analysed. If both univariate analysis and multivariate analysis were used in a given study, the survival data of multivariate analysis were preferably included.

\section{Quality assessment}

The Newcastle-Ottawa quality assessment scale $^{17}$ was employed for the assessment of included studies. Such a tool entails a scoring system ranging between 0 (bad) and 9 (excellent) for certain criteria pertinent to the study groups, such as selection, comparability, and outcomes. Studies were deemed of a high quality if the total score was $\geq 6$.

\section{Statistical analysis}

The meta-analysis was performed using RevMan 5.3 software (Review Manager, the Cochrane Collaboration, Oxford, United Kingdom). The pooled effects were estimated using HRs and their $95 \%$ CI for prognostic data, while odds ratio (OR) and their $95 \%$ CIs were used for analysing the relationship between low or high MCT expression levels and LNM or DM. The $\mathrm{I}^{2}$ statistic test was utilized to quantify the heterogeneity between studies, where a significant heterogeneity was considered at $\mathrm{I}^{2}>50 \%$ and subsequently a random-effect model should be used. If not, a fixed effect model was applied. The subgroup analysis was done for LNM and DM and their association with MCT1 and/or MCT4 expression according to sample size ( $<150$ versus $\geq 150$ ), cancer type, and quality score $(<7$ versus $\geq 7)$. Significant relationships were estimated at a $\mathrm{P}$ value $<0.05$.

\section{Results}

\section{Outcomes of the search process}

Figure 1 depicts the main findings of the search process. A total of 4322 records were initially obtained, from which 250 duplicates were identified across different scientific databases. With an additional three articles identified in the reference lists of the attained articles, 4075 records were screened for eligibility. Subsequently, 4053 articles were excluded through the screening of titles and abstracts, and the remaining 25 studies were thoroughly evaluated for inclusion. Ultimately, 20 articles met the inclusion criteria.

\section{Characteristics of the included studies}

Table $1^{18-37}$ demonstrates a chronologically ordered list of the included studies, which were published between 2010 and 2018. A total of 3831 patients ( $56.3 \%$ males) with different types of cancers were investigated. Colorectal cancer (CRC) was the most frequently studied type (in four studies) ${ }^{18-21}$ followed by hepatic cancer in three studies. ${ }^{22-24}$ Both MCT1 and MCT4 were investigated in six studies, ${ }^{21,25-29}$ while the remaining articles investigated either of them. All studies used immunohistochemistry (IHC) assays to quantify MCT expression. Five studies did not reveal their data relevant to MCT1 and/or MCT4 expression in metastasis, yet they were included as they reported the survival outcomes in patients 
with tumours expressing such MCTs. ${ }^{21,25,26,28,30,31}$ For quality assessment, all included studies scored equal to or greater than 6 , indicating that all of them were of a high quality.

\section{Expression of MCT1 and MCT4 in lymph node metastasis}

There was a significant heterogeneity between a total of 9 studies $^{19,20,27,29,32-34,36,37}$ that demonstrated LNM with the expression of MCT1 and MCT4 $\left(\mathrm{I}^{2}=77 \%\right.$ and $63 \%$, respectively). Interestingly, there was a significant association between MCT4 expression (high versus low) and LNM (OR=1.87, 95\%CI $=1.10$ $3.17, \mathrm{P}=0.02$, Figure $2 \mathrm{~B}$ ). However, such a relationship was unremarkable for high MCT1 expression, although LNM in gallbladder cancer showed a significant elevation of MCT1 expression (Figure 2A). ${ }^{36}$ The lack of significant effect of high MCT1 expression was still evident with subgroup analysis according to sample size, cancer type and quality score (Table 2).

\section{Expression of MCT1 and MCT4 in distant metastasis}

As with LNM, metastasis to distant organs was significantly associated with high MCT4 expression as compared to low expression $\left(\mathrm{OR}=2.18,95 \% \mathrm{CI}=1.65-2.86, \mathrm{P}<0.001, \mathrm{I}^{2}=42 \%\right.$, Figure $\left.2 \mathrm{D}\right)$. This association remained significant in colorectal ${ }^{19,20}$ and liver ${ }^{4,22,23}$ cancer, as per the results of subgroup analysis (Table 1). The overall effect of high MCT1 expression was not associated with DM, although higher odds ratios were shown in distant metastatic tumours in patients with clear cell renal cell carcinoma $(\mathrm{ccRCC})^{35}$ and gallbladder cancer $^{36}$ (Figure 2C). Remarkably, a significant association between high MCT1 expression and DM in small-sized studies, which analysed less than 150 samples $(\mathrm{OR}=20.64,95 \% \mathrm{CI}=2.58-164.89, \mathrm{P}<0.001$, Table 1$)$.

\section{The relationship between MCT1 and/or MCT4 expres- sion and prognosis}

Studies that investigated the survival analysis for MCT1 and MCT4 expression were based on a total of 1943 and 1853 patients' samples, respectively. Compared with low MCT4 expression, high MCT4 expression was significantly associated with poor prognosis

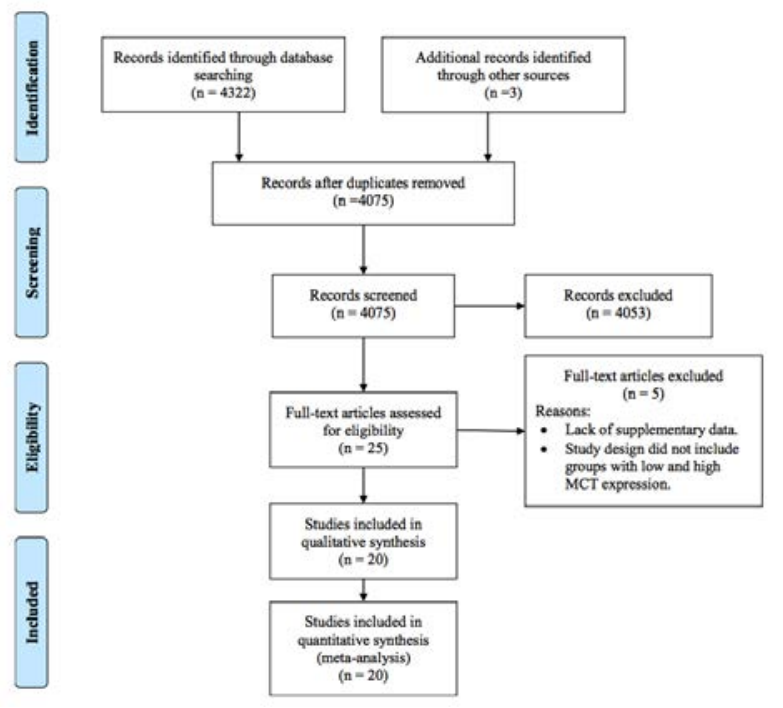

Figure 1. A flow chart showing the search strategy employed in this review.

Table 1. The characteristics of included studies.

\begin{tabular}{|c|c|c|c|c|c|c|c|c|c|}
\hline Author(s) & YOP & MA & $\begin{array}{l}\text { atien } \\
\mathrm{FE}\end{array}$ & $\mathrm{T}$ & Cancer & Studied protein & Metastasis & Analysis for HRs & Quality score \\
\hline Pinheiro et al. ${ }^{32}$ & 2010 & 0 & 249 & 249 & $\mathrm{BC}$ & MCT4 & LNM & $\mathrm{N} / \mathrm{A}$ & 8 \\
\hline Nakayama et al..$^{19}$ & 2012 & 59 & 46 & 105 & CRC & MCT4 & LNM, DM & M & 8 \\
\hline Choi et al..$^{33}$ & 2014 & 311 & 49 & 360 & UCB & MCT1, 4 & LNM, DM & M & 8 \\
\hline Eilertsen et $a .^{28}$ & 2014 & 253 & 82 & 335 & NSCLC & MCT4 & None & M & 8 \\
\hline Gao et al. ${ }^{22}$ & 2014 & 281 & 37 & 318 & $\mathrm{HCC}$ & MCT1 & DM & M & 6 \\
\hline Ohno et al..$^{23}$ & 2014 & 168 & 57 & 225 & $\mathrm{HCC}$ & MCT4 & DM & M & 7 \\
\hline Polanski et al. ${ }^{31}$ & 2014 & N/A & N/A & 78 & SCLC & MCT1 & None & M & 7 \\
\hline Yan et al. ${ }^{26}$ & 2014 & 85 & 58 & 143 & $\mathrm{GC}$ & MCT1, 4 & None & M & 8 \\
\hline Zhu et al. ${ }^{34}$ & 2014 & 59 & 40 & 99 & OSCC & MCT4 & LNM, DM & M & 7 \\
\hline Kim et al. ${ }^{35}$ & 2015 & 127 & 53 & 180 & ccRCC & MCT1 & DM & M & 6 \\
\hline Pinheiro et al ${ }^{30}$ & 2015 & 10 & 66 & 76 & ACC & MCT1, 4 & None & $\mathrm{U}$ & 6 \\
\hline Curry et al..$^{29}$ & 2016 & 14 & 32 & 46 & $\mathrm{TC}$ & MCT4 & LNM & N/A & 6 \\
\hline Martins et al. ${ }^{18}$ & 2016 & 308 & 179 & 487 & CRC & MCT4 & DM & M & 7 \\
\hline Petrides et al. ${ }^{21}$ & 2016 & 65 & 42 & 107 & CRC & MCT4 & None & M & 7 \\
\hline Shang et al..$^{36}$ & 2016 & 24 & 56 & 80 & GBC & MCT1, 4 & LNM, DM & M & 7 \\
\hline Johnson et al. ${ }^{25}$ & 2017 & 0 & 257 & 257 & $\mathrm{BC}$ & MCT1, 4 & None & M & 8 \\
\hline Latif et al..$^{37}$ & 2017 & 0 & 90 & 90 & $\mathrm{EC}$ & MCT1 & LNM & M & 8 \\
\hline Ruan et al..$^{27}$ & 2017 & 80 & 66 & 146 & LAC & MCT4 & LNM, DM & M & 8 \\
\hline Abe et al. ${ }^{20}$ & 2018 & 131 & 106 & 237 & CRC & MCT1, 4 & LNM, DM & N/A & 8 \\
\hline Chen et al. ${ }^{24}$ & 2018 & 182 & 31 & 213 & HCC* & MCT4 & DM & U & 6 \\
\hline
\end{tabular}

*Indicates performing analysis after hepatectomy. ACC, adrenocortical carcinoma; BC, breast cancer; ccRCC, clear cell renal cell carcinoma; CRC, colorectal cancer; DM, distant metastasis; EC, endometrial cancer; FE, female; GBC, gallbladder cancer; GC, gastric cancer; HCC, hepatocellular carcinoma; LAC, lung adenocarcinoma; LMN, lymph node metastasis; M, multivariate; MA, male; MCT, monocarboxylate transporter; N/A, not available; NSCLC, non-small-cell lung cancer; OSCC, oral squamous cell carcinoma; SCLC, small-cell lung cancer; T, total; TC, thyroid cancer; U, univariate; UCB, urothelial carcinoma of the bladder; YOP, year of publication. 
as revealed by shorter $\mathrm{OS}$ times $(\mathrm{HR}=1.78,95 \% \mathrm{CI}=1.49-2.13$, $\mathrm{P}<0.001$, Figure 3B) without heterogeneity between the included studies $\left(I^{2}=37 \%\right)$. However, survival analyses of the effects of high MCT1 expression revealed insignificant effects on prognosis and the studies were significantly heterogeneous $\left(\mathrm{P}=0.13, \mathrm{I}^{2}=81 \%\right.$,
Figure 3A). For DFS, MCT1 expression was studied only among 166 patients while MCT4 expression was analysed among 1355 patients. Both MCT1 and MCT4 expression were obviously associated with higher HRs, indicating poor prognosis. The relationship was stronger for MCT4 despite the significant heterogeneity

$\mathbf{A}$

\begin{tabular}{|c|c|c|c|c|c|c|c|c|c|c|}
\hline \multirow[b]{2}{*}{ Study or Subgroup } & \multicolumn{2}{|c|}{ High Expression } & \multicolumn{2}{|c|}{ Low Expression } & \multicolumn{2}{|r|}{ Odds Ratio } & \multirow{2}{*}{\multicolumn{3}{|c|}{$\begin{array}{c}\text { Odds Ratio } \\
\mathrm{M}-\mathrm{H}, \text { Random, } 95 \% \mathrm{Cl}\end{array}$}} & \\
\hline & Events & Total & Events & Total & Weight & M-H, Random, $95 \% \mathrm{Cl}$ & & & & \\
\hline Choi et al. 2014 & 27 & 130 & 25 & 230 & $29.6 \%$ & 2.15 [1.19, 3.89] & & & $\rightarrow-$ & \\
\hline Latif et al. 2017 & 17 & 41 & 20 & 48 & $26.0 \%$ & $0.99[0.43,2.31]$ & & & & \\
\hline Pinheiro et al. 2010 & 16 & 100 & 21 & 95 & $27.8 \%$ & $0.67[0.33,1.38]$ & & & & \\
\hline Shang et al.2016 & 35 & 62 & 2 & 18 & $16.6 \%$ & $10.37[2.19,49.02]$ & & & & \\
\hline Total $(95 \% \mathrm{Cl})$ & & 333 & & 391 & $100.0 \%$ & $1.65[0.68,3.98]$ & & & & \\
\hline Total events & 95 & & 68 & & & & & & & \\
\hline $\begin{array}{l}\text { Heterogeneity: Tau: } \\
\text { Test for overall effect }\end{array}$ & $\begin{array}{l}0.59 ; \mathrm{Chi}^{2} \\
z=1.12(\mathrm{P}\end{array}$ & $\begin{array}{l}3.09, \text { df } \\
3.26)\end{array}$ & $=3(P=0$ & 4): $1^{2}=$ & $77 \%$ & & 0.001 & $\begin{array}{c}0.1 \\
\text { Exp }\end{array}$ & \begin{tabular}{|rr}
1 & 10 \\
Favours [Lo & 10
\end{tabular} & 1000 \\
\hline
\end{tabular}

B

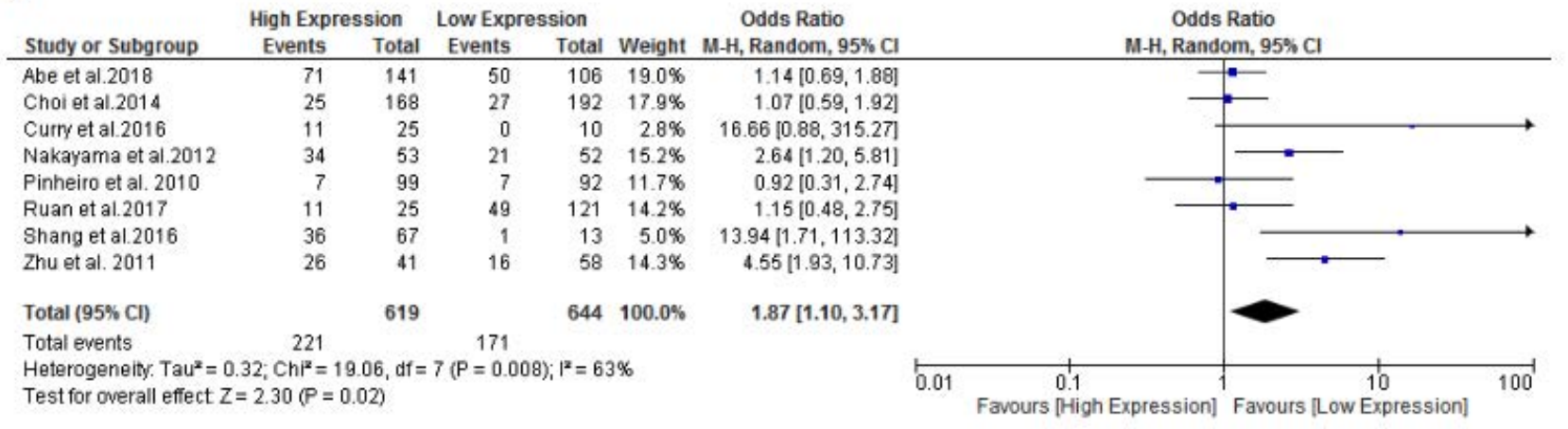

C

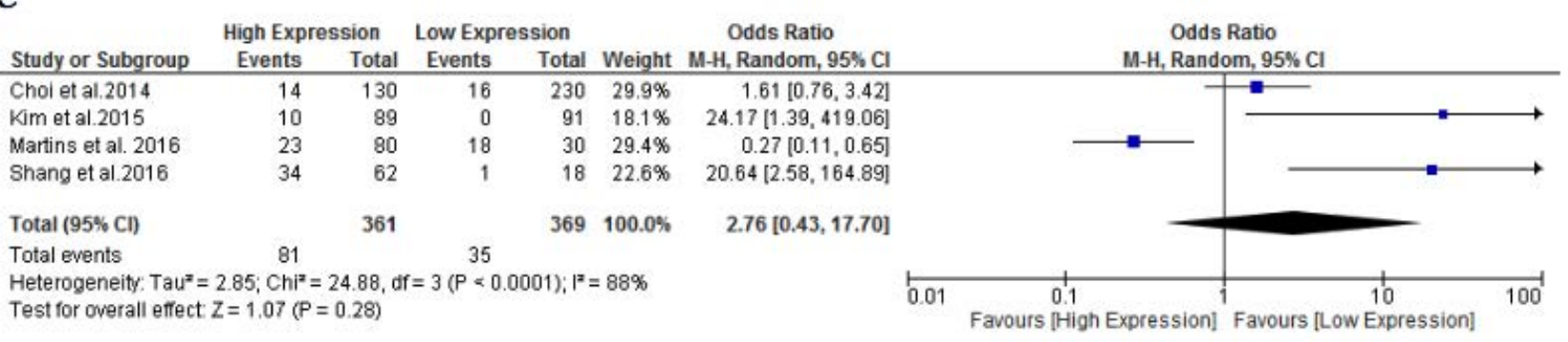

$\mathbf{D}$

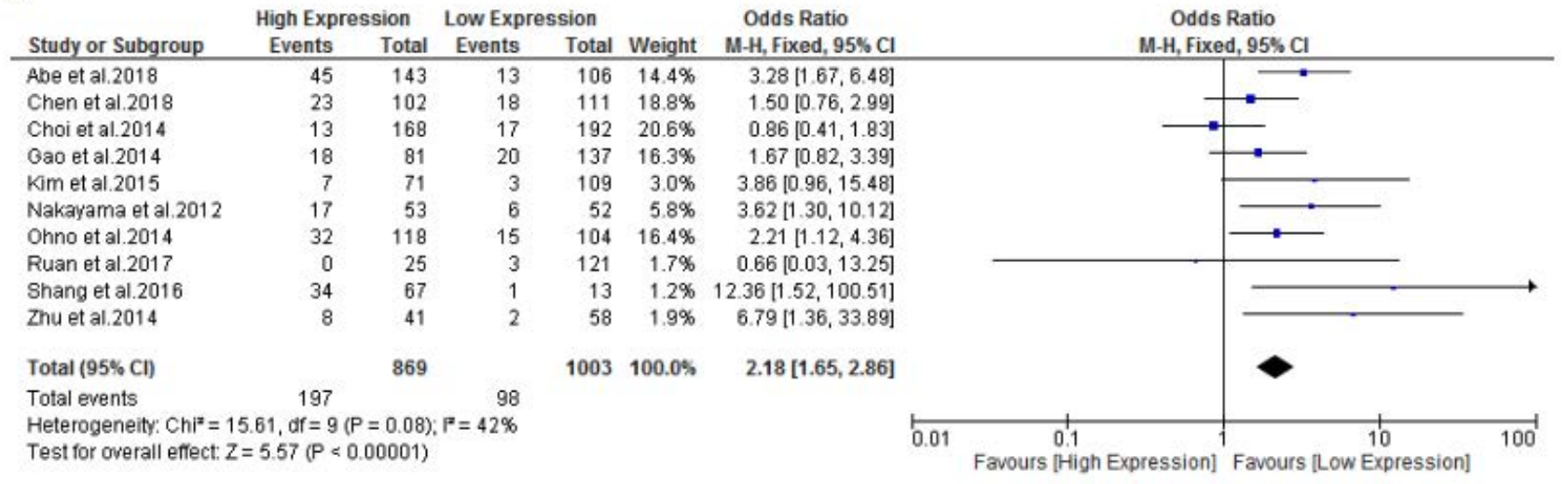

Figure 2. Forest plot of the relationship between lymph node metastasis and the expression of MCT1 (A) and MCT4 (B) as well as the relationship between distant metastasis and the expression of MCT1 (C) and MCT4 (D). 
between studies $\left(\mathrm{HR}=1.70,95 \% \mathrm{CI}=1.19-2.42, \mathrm{P}=0.003, \mathrm{I}^{2}=71 \%\right)$ while the relationship in two studies ${ }^{30,37}$ reporting their HRs for DFS in solid tumours was less apparent $(\mathrm{HR}=1.48,95 \% \mathrm{CI}=1.04$ $2.10, \mathrm{P}=0.03, \mathrm{I}^{2}=0 \%$, Figure $3 \mathrm{C}$ and $\mathrm{D}$ ).

\section{Discussion}

The biological implication of proton-dependent MCTs emerges from their integrative roles in transporting short-chain fatty acids, lactate and pyruvate in a variety of cells, including malignant cells, and thus MCTs have multiple pathologic implications. Given the importance of monocarboxylate compounds, including lactate, as well as $\mathrm{pH}$ homeostasis for the glycolytic metabolic pathways in cancer cells, it is not surprising that the rel- evant MCTs have gained increasing attention in cancer biology and its potential progression to a metastatic phenotype. Focusing on the latter aspect, increased lactate levels are significantly associated with metastasis in a considerable number of cancer types, such as cancers of the cervix, ${ }^{38,39}$ rectum, ${ }^{40}$ and head and neck. ${ }^{41}$ Actually, lactate can be involved in the signalling pathways of angiogenesis, immune system inhibition, and resistance to radiotherapy. ${ }^{42-44}$ For the implication of lactate transporters, this study has demonstrated that high MCT4 expression was consistently associated with LNM and DM in different types of cancer and yielded a remarkable shortening of OS and DFS. However, cancer metastasis was not associated with elevated MCT1 expression and it induced a poor prognostic effect only in DFS analysis (Table 3). ${ }^{45-55}$

The variation in expression between both proteins could be explained by the relatively increased tendency of MCT4 expres-

Table 2. Subgroups analysis for the association between metastasis and the studied MCTs.

\begin{tabular}{|c|c|c|c|c|c|c|c|c|}
\hline \multirow[t]{2}{*}{ Variable } & \multicolumn{4}{|c|}{ MCT1 } & \multicolumn{4}{|c|}{ MCT4 } \\
\hline & Studies & Model $\left(1^{20} \%\right)$ & HR [95\% CI] & $\mathbf{P}$ & Studies & Model ( $\left.{ }^{2} \%\right)$ & HR [95\% CI] & $\mathbf{P}$ \\
\hline \multicolumn{9}{|c|}{ LNM } \\
\hline \multicolumn{9}{|l|}{ Sample size } \\
\hline$<150$ & 2 & $\mathrm{R}(83)$ & $1.22[0.39,3.89]$ & 0.73 & 5 & $\mathrm{R}(56)$ & $3.26[1.48,7.19]$ & 0.003 \\
\hline$\geq 150$ & 2 & $\mathrm{R}(86)$ & $2.93[0.28,30.16]$ & 0.37 & 3 & $\mathrm{~F}(0)$ & $1.09[0.76,1.56]$ & 0.66 \\
\hline \multicolumn{9}{|l|}{ Cancer type } \\
\hline Breast cancer & 1 & $\mathrm{R}(\mathrm{N} / \mathrm{A})$ & $0.67[0.33,1.38]$ & 0.28 & 1 & $\mathrm{R}(\mathrm{N} / \mathrm{A})$ & $0.92[0.31,2.74]$ & 0.89 \\
\hline CRC & - & - & & - & 2 & $\mathrm{R}(68)$ & $1.64[0.72,3.71]$ & 0.24 \\
\hline Other types & 3 & $\mathrm{R}(72)$ & $2.31[0.85,6.30]$ & 0.10 & 5 & $\mathrm{R}(73)$ & $2.69[1.05,6.92]$ & 0.04 \\
\hline \multicolumn{9}{|l|}{ Quality score } \\
\hline$\geq 7$ & 4 & $\mathrm{R}(77)$ & $1.65[0.68,3.98]$ & 0.26 & 7 & $\mathrm{R}(63)$ & $1.74[1.04,2.91]$ & 0.04 \\
\hline$<7$ & - & - & - & - & 1 & $\mathrm{R}(\mathrm{N} / \mathrm{A})$ & $16.66[0.88,315.27]$ & 0.06 \\
\hline \multicolumn{9}{|c|}{ DM } \\
\hline \multicolumn{9}{|l|}{ Sample size } \\
\hline$<150$ & 1 & $\mathrm{R}(\mathrm{N} / \mathrm{A})$ & $20.64[2.58,164.89]$ & $<0.001$ & 4 & $\mathrm{~F}(0)$ & $4.67[2.27,9.63]$ & $<0.001$ \\
\hline$\geq 150$ & 3 & $\mathrm{R}(87)$ & $1.42[0.22,9.02]$ & 0.71 & 6 & $\mathrm{~F}(41)$ & $1.88[1.40,2.54]$ & $<0.001$ \\
\hline \multicolumn{9}{|l|}{ Cancer type } \\
\hline CRC & 1 & $\mathrm{R}(\mathrm{N} / \mathrm{A})$ & $0.27[0.11,0.65]$ & 0.003 & 2 & $\mathrm{~F}(0)$ & $3.38[1.92,5.96]$ & $<0.001$ \\
\hline $\mathrm{HCC}$ & - & - & - & - & 3 & $\mathrm{~F}(0)$ & $1.78[1.20,2.65]$ & 0.004 \\
\hline Other types & 3 & $\mathrm{R}(77)$ & $7.31[0.79,67.51]$ & 0.08 & 5 & $R(65)$ & $2.79[0.87,8.99]$ & 0.09 \\
\hline \multicolumn{9}{|l|}{ Quality score } \\
\hline$\geq 7$ & 3 & $\mathrm{R}(90)$ & $1.67[0.25,11.33]$ & 0.60 & 7 & $\mathrm{R}(55)$ & $2.57[1.40,4.70]$ & 0.002 \\
\hline$<7$ & 1 & $\mathrm{R}(\mathrm{N} / \mathrm{A})$ & $24.17[1.39,419.06]$ & 0.03 & 3 & $\mathrm{~F}(0)$ & $1.76[1.11,2.79]$ & 0.02 \\
\hline
\end{tabular}

CRC, colorectal cancer; DM, distant metastasis; F, fixed; HCC, hepatocellular carcinoma; LMN, lymph node metastasis; MCT, monocarboxylate transporter; N/A, not applicable; R, random.

Table 3. The biological implications of MCT1 and MCT4.

\begin{tabular}{|c|c|c|c|}
\hline Item & MCT1 & MCT4 & Reference \\
\hline Main substrate & $\begin{array}{l}\text { Lactate, pyruvate, butyrate, acetoacetate, } \\
\text { } \text {-hydroxybutyrate, XP13512, GHB }\end{array}$ & Lactate, pyruvate, acetoacetate, $\beta$-hydroxybutyrate & $\begin{array}{l}\text { Halestrap et } \text { al. }^{45} \\
\text { Pierre and Pellerin }\end{array}$ \\
\hline Tissue expression & $\begin{array}{l}\text { Kidney, stomach, intestine, liver, heart, } \\
\text { skeletal muscle, prostate, testis, eye, lung, } \\
\text { placenta, blood and brain }\end{array}$ & $\begin{array}{l}\text { Skeletal muscle, kidney, liver, brain, stomach, testis, } \\
\text { eye, leukocytes, placenta, lung, heart, blood, } \\
\text { chondrocytes }\end{array}$ & $\begin{array}{l}\text { Halestrap et } \text { al. }^{45} \\
\text { Pierre and Pellerin } \\
\\
\text { Pellerin } \text { et } \text { al. }\end{array}$ \\
\hline Targeting drugs/inhibitors & $\begin{array}{l}\text { - AZD3965 (Cayman Chemical Company) } \\
\text { - 7ACC2 (Cayman Chemical Company) } \\
\text { - Syrosingopine (INDOFINE Chemical } \\
\text { Company, Inc.) }\end{array}$ & Syrosingopine & $\begin{array}{l}\text { Curtis et al. }{ }^{48} \\
\text { Halford et al. }{ }^{49} \\
\text { Corbetet et al. } .^{50} \\
\text { Benjamin et } \text { al. } .^{51}\end{array}$ \\
\hline $\begin{array}{l}\text { Clinical relevance } \\
\text { of aberrant expression }\end{array}$ & $\begin{array}{l}\text { - Multiple cancers (colon, breast, prostate, } \\
\text { pancreas, glioblastoma, cervix) } \\
\text { - EIHI, IBD, ketoacidosis }\end{array}$ & $\begin{array}{l}\text { - Multiple cancers (colon, breast, prostate, } \\
\text { pancreas, ccRCC) } \\
\text { - Obesity, RA }\end{array}$ & $\begin{array}{l}\text { Thibault et al. }{ }^{52} \\
\text { Tosur et al. } .^{53} \\
\text { Balasubramaniam et al. } .^{54} \\
\text { Fisel et al. } .^{55}\end{array}$ \\
\hline
\end{tabular}

ccRCC, clear cell renal cell carcinoma; EIHI, exercise induced hyperinsulinism; IBD, inflammatory bowel disease; RA, rheumatoid arthritis. 
$\mathbf{A}$

\begin{tabular}{|c|c|c|c|c|c|c|c|c|}
\hline Study or Subgroup & log[Hazard Ratio] & SE & Weight & $\begin{array}{c}\text { Hazard Ratio } \\
\text { IV, Random, } 95 \% \mathrm{Cl}\end{array}$ & & $\begin{array}{r}\text { Hazard } \\
\mathrm{IV} \text {, Randor }\end{array}$ & $\begin{array}{l}\text { d Ratio } \\
\mathrm{om}, 95 \% \mathrm{Cl}\end{array}$ & \\
\hline Choi et al.2014 & 0.8109 & 0.3792 & $10.8 \%$ & $2.25[1.07,4.73]$ & & & & \\
\hline Eilertsen et al. 2014 & -0.6349 & 0.1973 & $13.2 \%$ & $0.53[0.36,0.78]$ & & $\rightarrow$ & & \\
\hline Johnson et al.2017 & 0.6366 & 0.3299 & $11.5 \%$ & $1.89[0.99,3.61]$ & & & & \\
\hline Kim et al. 2015 & 1.454 & 0.4363 & $10.0 \%$ & $4.28[1.82,10.07]$ & & & & \\
\hline Latif et al. 2017 & 0.4837 & 0.2317 & $12.8 \%$ & $1.62[1.03,2.55]$ & & & & \\
\hline Martins et al. 2016 & -0.3653 & 0.4112 & $10.4 \%$ & $0.69[0.31,1.55]$ & & & & \\
\hline Pinheiro et al. 2015 & 0.8198 & 0.3983 & $10.6 \%$ & $2.27[1.04,4.96]$ & & & & \\
\hline Polański et al. 2014 & -0.4308 & 0.4482 & $9.9 \%$ & $0.65[0.27,1.56]$ & & & & \\
\hline Shang et al. 2016 & 0.8398 & 0.3827 & $10.8 \%$ & $2.32[1.09,4.90]$ & & & & \\
\hline Total $(95 \% \mathrm{Cl})$ & & & $100.0 \%$ & $1.47[0.89,2.40]$ & & & & \\
\hline \multicolumn{5}{|c|}{$\begin{array}{l}\text { Heterogeneity: } \text { Tau }^{2}=0.44 ; \mathrm{Chi}^{2}=41.10, \mathrm{df}=8(\mathrm{P}<0.00001) ; I^{2}=81 \% \\
\text { Test for overall effect } Z=1.52(P=0.13)\end{array}$} & 0. & 0.1 & & 100 \\
\hline
\end{tabular}

B

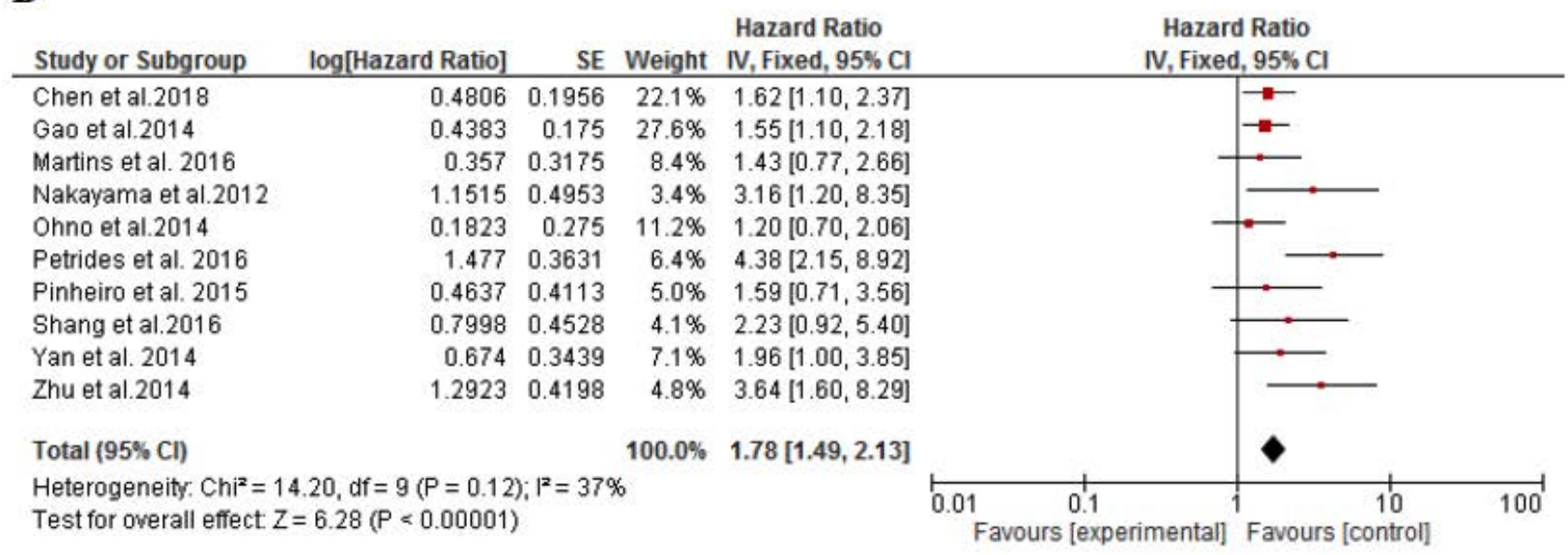

C

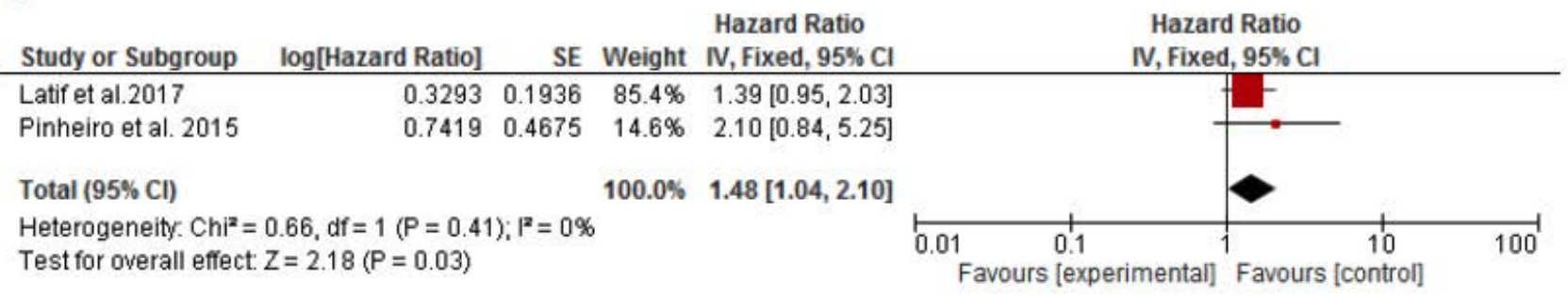

\section{D}

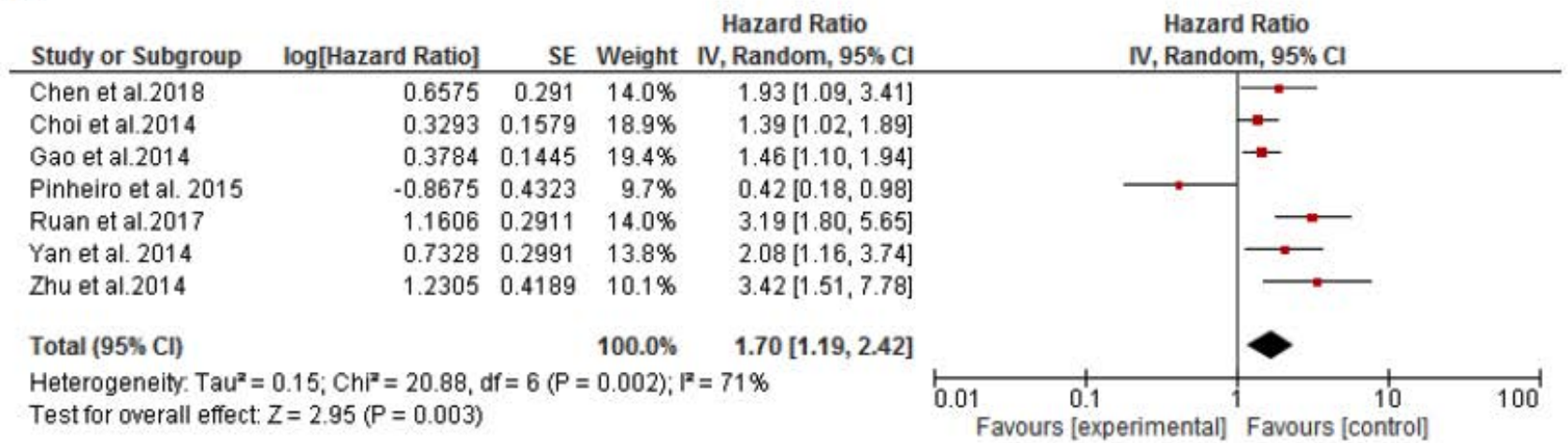

Figure 3. Forest plot depicting the relationship between the overall survival and the expression of MCT1 (A) and MCT4 (B) as well as the relationship between disease-free survival and the expression of MCT1 (A) and MCT4 (B). 
sion in cells exhibiting high rates of glycolysis, such as cancer cells, when compared to MCT1 $1{ }^{11}$ In vitro experiments have, to a degree, supported this finding through a significant MCT4 upregulation in the stroma of cancer-associated fibroblasts when they were cultured with breast cancer cell lines, due to activation of hypoxia-inducible factor-1a (HIF-1 $\alpha$ ), while MCT1 protein expression was only limited to epithelial cancer cells. ${ }^{56,57}$ Importantly, the correlation between HIF- $1 \alpha$ and MCT4 is of great relevance since the former is a potent regulator of the metabolic switch in metastatic tumour cells. ${ }^{58,59}$ The involvement of the MCT4-inducing transcription factor, HIF-1 $\alpha$, in metastasis has been identified in several critical aspects, including stem cell maintenance, angiogenesis, metabolic reprogramming, metastasis and cancer cell invasion, ${ }^{60}$ while disruption of HIF-1 $\alpha$ activity in mice injected with triple-negative breast cancer cells led to favourable effects on LNM and DM to the lungs. ${ }^{61}$

Likewise, Gallagher et al. ${ }^{62}$ have reported that MCT1 was the most predominant MCT member in normal breast tissue, while the metastatic MDA-MB-231 cells showed high MCT4 expression. The authors suggested that several genes that encode glycolytic transporters may contribute to such expression patterns, such as GLUT1. ${ }^{62}$ Meijer et al. ${ }^{63}$ have revealed a difference in the expression of MCT4 and GLUT1 between highly-glycolytic adenocarcinomas and squamous cell non-small-cell lung cancer. In addition, MCT4 can act synergistically with its chaperone protein CD147, which is a known inducer of extracellular matrix metalloproteinase, in cancer cells to promote metastasis via lowering the $\mathrm{pH}$ of the tumour microenvironment and increasing the rates of degradation of extracellular matrix through enhancing lactate efflux. The elevated co-expression of MCT4, CD147 and GLUT1 has been also identified in papillary renal cell carcinoma ${ }^{64}$ whereas other reports emphasized the potential role of MCT4 and CD147 expression in the metabolic remodelling of prostate ${ }^{65}$ and pancreatic cancers. ${ }^{66}$

Beside its role in metastasis biology, the current study revealed that MCT4 is regarded as a clinical biomarker of cancer-related mortality. MCT4 was significantly expressed and associated with higher tumour grades as well as poorer clinical outcomes in patients with breast cancer, oral squamous cell carcinoma, and ccRCC. ${ }^{34,67,68}$ Although MCT1 was upregulated in multiple types of cancer, such as prostate and breast cancer, ${ }^{65,69}$ its association with poor prognostic markers was only significant in melanomas. ${ }^{70}$ Following lactate transport via MCT1, it is oxidized to pyruvate which accumulates in cancer cells and suppresses prolyl-hydroxylase 2, leading to activation of HIF-1 and NF- $\kappa$ B. ${ }^{71}$ Both factors can supposedly have a role in inducing metastasis. ${ }^{72,73}$

In line with the biological relevance and prognostic role of MCT4, and to a less extent MCT1, it is essential that one assesses their potential in targeted cancer therapies as either single anticancer agents or in combination with other chemotherapeutic drugs. As such, several MCT inhibitors have been developed, such as AR-C155858 and 7ACC2. ${ }^{74,75}$ In addition, recent evidence has shown that AZD3965, an MCT1 inhibitor, has led to intracellular lactate accumulation in 120 samples of diffuse large B-cell lymphoma which expressed low levels of MCT4. ${ }^{76}$ However, Bola et $a l .{ }^{77}$ found that gastric and small cell lung cancer cells employed a compensatory mechanism by increasing the rate of reliance on glucose as a source of energy, as demonstrated by glycolytic flux analysis, thereby AZD3965 can be effective only in the hypoxic areas of tumours. In the context of metastasis, migration and invasion of cancer cells could be disrupted via downregulation or pharmacological inhibition of MCT1 or MCT4, as shown in multiple experimental studies. ${ }^{62,78-80}$

This meta-analytic approach to the impact of lactate-transport- ing MCTs in metastatic progression may highlight the importance of these proteins and further encourage conducting reliable investigations aimed at reducing the burden of metastasis. However, some limitations might affect the interpretation of the outcomes. Analysis of MCT expression by IHC might be based on different methodological approaches in terms of relying on heterogeneous antibodies or the arbitrary scoring methods. This could be resolved by methodological validation and using unified commercial reagents. The number of studies concerned with the survival analysis of MCT1 expression might be insufficient to reveal a statistical significance. Finally, the variation in sample sizes and methodological flaws between studies might lead to a reported statistical heterogeneity in several instances.

\section{Conclusions}

In conclusion, we have shown that MCT4 is highly expressed in the metastasis of several types of cancers, such as colorectal and hepatic cancer. This effect is mediated by promoting lactate transport that enhances the invasion and migration of metastatic cells. An increase in the expression levels of MCT4, and to a less extent MCT1, in patients with cancer was also correlated with poor prognosis. However, formal confirmatory evidence that MCT inhibition can reduce metastasis and mortality is still lacking. This highlights the importance of developing relevant therapeutic interventions that target these proteins and their pertinent molecular pathways.

\section{References}

1. Rodenhiser DI, Chambers AF. Cancer metastasis: tracking and attacking a moving target. In: Maxwell C, Roskelley C, eds. Genomic instability and cancer metastasis: mechanisms, emerging themes, and novel therapeutic strategies. Cham: Springer International Publishing; 2015. pp 1-13.

2. Bacac M, Stamenkovic I. Metastatic cancer cell. Annu Rev Pathol 2008;3:221-47.

3. Tarin D. Comparisons of metastases in different organs: biological and clinical implications. Clin Cancer Res 2008;14:1923-5.

4. Chen M-T, Sun H-F, Zhao Y, et al. Comparison of patterns and prognosis among distant metastatic breast cancer patients by age groups: a SEER population-based analysis. Sci Rep 2017;7:9254.

5. Qian C-N, Mei Y, Zhang J. Cancer metastasis: issues and challenges. Chin J Cancer 2017;36:38-

6. Su Z, Yang Z, Xu Y, et al. Apoptosis, autophagy, necroptosis, and cancer metastasis. Mol Cancer 2015;14:48.

7. Wang R-A, Lu Y-Y, Fan D-M. Reasons for cancer metastasis: a holistic perspective. Mol Clin Oncol 2015;3:1199-202.

8. Warburg O. Uber den Stoffwechsel der Karzinomezellen. Biochem Z 1924;152:309-44.

9. Muramatsu T, Miyauchi T. Basigin (CD147): a multifunctional transmembrane protein involved in reproduction, neural function, inflammation and tumor invasion. Histol Histopathol 2003;18:981-7.

10. Halestrap AP, Price NT. The proton-linked monocarboxylate transporter (MCT) family: structure, function and regulation. Biochem J 1999;343:281-99.

11. Halestrap AP. The SLC16 gene family - structure, role and regulation in health and disease. Mol Aspects Med 2013;34:337- 
49.

12. Froberg MK, Gerhart DZ, Enerson BE, et al. Expression of monocarboxylate transporter MCT1 in normal and neoplastic human CNS tissues. Neuroreport 2001;12:761-5.

13. Pinheiro C, Reis RM, Ricardo S, et al. Expression of monocarboxylate transporters 1,2 , and 4 in human tumours and their association with CD147 and CD44. J Biomed Biotechnol 2010;2010:427694.

14. Moher D, Liberati A, Tetzlaff J, et al. Preferred reporting items for systematic reviews and meta-analyses: the PRISMA statement. PLoS Med 2009; 6:e1000097.

15. Zhang S, Zhang D, Yi S, et al. The relationship of lymphatic vessel density, lymphovascular invasion, and lymph node metastasis in breast cancer: a systematic review and metaanalysis. Oncotarget 2017;8:2863-73.

16. Song YJ, Shin SH, Cho JS, et al. The role of lymphovascular invasion as a prognostic factor in patients with lymph nodepositive operable invasive breast cancer. J Breast Cancer 2011;14:198-203.

17. Stang A. Critical evaluation of the Newcastle-Ottawa scale for the assessment of the quality of nonrandomized studies in meta-analyses. Eur J Epidemiol 2010;25:603-5.

18. Martins SF, Amorim R, Viana-Pereira M, et al. Significance of glycolytic metabolism-related protein expression in colorectal cancer, lymph node and hepatic metastasis. BMC Cancer 2016;16:535.

19. Nakayama Y, Torigoe T, Inoue Y, et al. Prognostic significance of monocarboxylate transporter 4 expression in patients with colorectal cancer. Exp Ther Med 2012;3:25-30.

20. Abe Y, Nakayama Y, Katsuki T, et al. The prognostic significance of the expression of monocarboxylate transporter 4 in patients with right- or left-sided colorectal cancer. Asia Pac J Clin Oncol 2018 [Epub ahead of print].

21. Petrides C, Neofytou K, Agrogiannis G, et al. Monocarboxylate transporter 4 as a prognostic biomarker in patients with colorectal cancer and liver metastases. Int J Surg 2016;5:37-43.

22. Gao HJ, Zhao MC, Zhang YJ, et al. Monocarboxylate transporter 4 predicts poor prognosis in hepatocellular carcinoma and is associated with cell proliferation and migration. J Cancer Res Clin Oncol. 2015;141:1151-62.

23. Ohno A, Yorita K, Haruyama Y, et al. Aberrant expression of monocarboxylate transporter 4 in tumour cells predicts an unfavourable outcome in patients with hepatocellular carcinoma. Liver Int 2014;34:942-52.

24. Chen HL, OuYang HY, Le Y, et al. Aberrant MCT4 and GLUT1 expression is correlated with early recurrence and poor prognosis of hepatocellular carcinoma after hepatectomy. Cancer Med 2018;7:5339-50.

25. Johnson JM, Cotzia P, Fratamico R, et al. MCT1 in invasive ductal carcinoma: monocarboxylate metabolism and aggressive breast cancer. Front Cell Dev Biol 2017;5:27.

26. Yan P, Li YH, Tang ZJ, et al. High monocarboxylate transporter 4 protein expression in stromal cells predicts adverse survival in gastric cancer. Asian Pac J Cancer Prev 2014;15:8923-9.

27. Ruan Y, Zeng F, Cheng Z, et al. High expression of monocarboxylate transporter 4 predicts poor prognosis in patients with lung adenocarcinoma. Oncol Lett 2017;14:5727-34.

28. Eilertsen M, Andersen S, Al-Saad S, et al. Monocarboxylate transporters 1-4 in NSCLC: MCT1 is an independent prognostic marker for survival. PLoS One 2014;9:e105038-e.
29. Curry JM, Tassone P, Cotzia P, et al. Multicompartment metabolism in papillary thyroid cancer. Laryngoscope 2016;126:2410-8.

30. Pinheiro C, Granja S, Longatto-Filho A, et al. Metabolic reprogramming: a new relevant pathway in adult adrenocortical tumors. Oncotarget 2015;6:44403-21.

31. Polanski R, Hodgkinson CL, Fusi A, et al. Activity of the monocarboxylate transporter 1 inhibitor AZD3965 in small cell lung cancer. Clin Cancer Res 2014;20:926-37.

32. Pinheiro C, Albergaria A, Paredes J, et al. Monocarboxylate transporter 1 is up-regulated in basal-like breast carcinoma. Histopathology 2010;56:860-7.

33. Choi JW, Kim Y, Lee JH, et al. Prognostic significance of lactate/proton symporters MCT1, MCT4, and their chaperone CD147 expressions in urothelial carcinoma of the bladder. Urology 2014;84:245.e9-15.

34. Zhu J, Wu Y-N, Zhang W, et al. Monocarboxylate transporter 4 facilitates cell proliferation and migration and is associated with poor prognosis in oral squamous cell carcinoma patients. PLoS One 2014;9:e87904-e.

35. Kim Y, Choi JW, Lee JH, et al. Expression of lactate/H(+) symporters MCT1 and MCT4 and their chaperone CD147 predicts tumor progression in clear cell renal cell carcinoma: immunohistochemical and The Cancer Genome Atlas data analyses. Hum Pathol 2015;46:104-12.

36. Shang R, Dai B, Ruan B, et al. Expression of monocarboxylate transporters in gallbladder cancer and their prognostic clinical significance. Int J Clin Exp Pathol 2016;9:1901-8.

37. Latif A, Chadwick AL, Kitson SJ, et al. Monocarboxylate Transporter 1 (MCT1) is an independent prognostic biomarker in endometrial cancer. BMC Clin Pathol 2017;17:27.

38. Walenta S, Wetterling M, Lehrke M, et al. High lactate levels predict likelihood of metastases, tumor recurrence, and restricted patient survival in human cervical cancers. Cancer Res 2000;60:916-21.

39. Schwickert G, Walenta S, Sundfor $\mathrm{K}$, et al. Correlation of high lactate levels in human cervical cancer with incidence of metastasis. Cancer Res 1995;55:4757-9.

40. Walenta S, Chau TV, Schroeder T, et al. Metabolic classification of human rectal adenocarcinomas: a novel guideline for clinical oncologists? J Cancer Res Clin Oncol 2003;129:321-6.

41. Brizel DM, Schroeder T, Scher RL, et al. Elevated tumor lactate concentrations predict for an increased risk of metastases in head-and-neck cancer. Int $\mathrm{J}$ Radiat Oncol Biol Phys 2001;51:349-53.

42. Sattler UG, Hirschhaeuser F, Mueller-Klieser WF. Manipulation of glycolysis in malignant tumors: fantasy or therapy? Curr Med Chem 2010;17:96-108.

43. Goetze K, Walenta S, Ksiazkiewicz M, et al. Lactate enhances motility of tumor cells and inhibits monocyte migration and cytokine release. Int J Oncol 2011;39:453-63.

44. Yabu M, Shime H, Hara H, et al. IL-23-dependent and -independent enhancement pathways of IL-17A production by lactic acid. Int Immunol 2011;23:29-41.

45. Halestrap AP, Meredith D. The SLC16 gene family-from monocarboxylate transporters (MCTs) to aromatic amino acid transporters and beyond. Pflugers Arch 2004;447:619-28.

46. Pierre K, Pellerin L. Monocarboxylate transporters in the central nervous system: distribution, regulation and function. J Neurochem. 2005;94:1-14.

47. Pellerin L, Bergersen LH, Halestrap AP, et al. Cellular and subcellular distribution of monocarboxylate transporters in cul- 
tured brain cells and in the adult brain. J Neurosci Res 2005; 79:55-64.

48. Curtis NJ, Mooney L, Hopcroft L, et al. Pre-clinical pharmacology of AZD3965, a selective inhibitor of MCT1: DLBCL, NHL and Burkitt's lymphoma anti-tumor activity. Oncotarget 2017;8:69219-36.

49. Halford SER, Jones P, Wedge S, et al. A first-in-human first-inclass (FIC) trial of the monocarboxylate transporter 1 (MCT1) inhibitor AZD3965 in patients with advanced solid tumours. J Clin Oncol 2017;35:2516.

50. Corbet C, Bastien E, Draoui N, et al. Interruption of lactate uptake by inhibiting mitochondrial pyruvate transport unravels direct antitumor and radiosensitizing effects. Nat Commun 2018;9:1208.

51. Benjamin D, Robay D, Hindupur SK, et al. Dual inhibition of the lactate transporters MCT1 and MCT4 is synthetic lethal with metformin due to NAD+ depletion in cancer cells. Cell Rep 2018;25:3047-58.e4.

52. Thibault R, De Coppet P, Daly K, et al. Down-regulation of the monocarboxylate transporter 1 is involved in butyrate deficiency during intestinal inflammation. Gastroenterology 2007;133:1916-27.

53. Tosur M, Jeha GS. A Novel intragenic SLC16A1 mutation associated with congenital hyperinsulinism. Glob Pediatr Health 2017;4:2333794x17703462.

54. Balasubramaniam S, Lewis B, Greed L, et al. Heterozygous monocarboxylate transporter 1 (MCT1, SLC16A1) deficiency as a cause of recurrent ketoacidosis. JIMD Rep 2016;29:33-8.

55. Fisel P, Schaeffeler E, Schwab M. Clinical and functional relevance of the monocarboxylate transporter family in disease pathophysiology and drug therapy. Clin Transl Sci 2018;11:352-64.

56. Whitaker-Menezes D, Martinez-Outschoorn UE, Lin Z, et al. Evidence for a stromal-epithelial "lactate shuttle" in human tumors: MCT4 is a marker of oxidative stress in cancer-associated fibroblasts. Cell Cycle 2011;10:1772-83.

57. Ullah MS, Davies AJ, Halestrap AP. The plasma membrane lactate transporter MCT4, but not MCT1, is up-regulated by hypoxia through a HIF-1alpha-dependent mechanism. J Biol Chem 2006;281:9030-7.

58. Semenza GL, Artemov D, Bedi A, et al. 'The metabolism of tumours': 70 years later. Novartis Found Symp 2001;240:25160; discussion 60-4.

59. Kim JW, Dang CV. Multifaceted roles of glycolytic enzymes. Trends Biochem Sci 2005;30:142-50.

60. Semenza GL. Hypoxia-inducible factors: mediators of cancer progression and targets for cancer therapy. Trends Pharmacol Sci 2012;33:207-14.

61. Zhang H, Wong CC, Wei H, et al. HIF-1-dependent expression of angiopoietin-like 4 and L1CAM mediates vascular metastasis of hypoxic breast cancer cells to the lungs. Oncogene. 2012;31:1757-70.

62. Gallagher SM, Castorino JJ, Wang D, et al. Monocarboxylate transporter 4 regulates maturation and trafficking of CD147 to the plasma membrane in the metastatic breast cancer cell line MDA-MB-231. Cancer Res 2007;67:4182-9.

63. Meijer TW, Schuurbiers OC, Kaanders JH, et al. Differences in metabolism between adeno- and squamous cell non-small cell lung carcinomas: spatial distribution and prognostic value of GLUT1 and MCT4. Lung Cancer 2012;76:316-23.

64. Almeida L, Silva R, Cavadas B, et al. GLUT1, MCT1/4 and CD147 overexpression supports the metabolic reprogramming in papillary renal cell carcinoma. Histol Histopathol 2017;32:1029-40.
65. Pértega-Gomes N, Vizcaíno JR, Miranda-Gonçalves V, et al. Monocarboxylate transporter 4 (MCT4) and CD147 overexpression is associated with poor prognosis in prostate cancer. BMC Cancer 2011;11:312.

66. Baek G, Tse YF, Hu Z, et al. MCT4 defines a glycolytic subtype of pancreatic cancer with poor prognosis and unique metabolic dependencies. Cell Rep 2014;9:2233-49.

67. Luz MCdB, Perez MM, Azzalis LA, et al. Evaluation of MCT1, MCT4 and CD147 genes in peripheral blood cells of breast cancer patients and their potential use as diagnostic and prognostic markers. Int J Mol Sci 2017;18:170.

68. Cao YW, Liu Y, Dong Z, et al. Monocarboxylate transporters MCT1 and MCT4 are independent prognostic biomarkers for the survival of patients with clear cell renal cell carcinoma and those receiving therapy targeting angiogenesis. Urol Oncol 2018;36:311.e15-e25.

69. Pinheiro C, Sousa B, Albergaria A, et al. GLUT1 and CAIX expression profiles in breast cancer correlate with adverse prognostic factors and MCT1 overexpression. Histol Histopathol 2011;26:1279-86.

70. Pinheiro C, Miranda-Gonçalves V, Longatto-Filho A, et al. The metabolic microenvironment of melanomas: Prognostic value of MCT1 and MCT4. Cell cycle (Georgetown, Tex) 2016;15:1462-70.

71. Payen VL, Porporato PE, Baselet B, et al. Metabolic changes associated with tumor metastasis, part 1: tumor $\mathrm{pH}$, glycolysis and the pentose phosphate pathway. Cell Mol Life Sci 2016;73:1333-48.

72. Andela VB, Schwarz EM, Puzas JE, et al. Tumor metastasis and the reciprocal regulation of prometastatic and antimetastatic factors by nuclear factor kappaB. Cancer Res 2000;60:6557-62.

73. Lu X, Kang Y. Hypoxia and hypoxia-inducible factors: master regulators of metastasis. Clin Cancer Res 2010;16:5928-35.

74. Ovens MJ, Manoharan C, Wilson MC, et al. The inhibition of monocarboxylate transporter 2 (MCT2) by AR-C155858 is modulated by the associated ancillary protein. Biochem $\mathrm{J}$ 2010;431:217-25.

75. Draoui N, Schicke O, Seront E, et al. Antitumor activity of 7aminocarboxycoumarin derivatives, a new class of potent inhibitors of lactate influx but not efflux. Mol Cancer Ther 2014;13:1410-8.

76. Noble RA, Bell N, Blair H, et al. Inhibition of monocarboxyate transporter 1 by AZD3965 as a novel therapeutic approach for diffuse large B-cell lymphoma and Burkitt lymphoma. Haematologica 2017;102:1247-57.

77. Bola BM, Chadwick AL, Michopoulos F, et al. Inhibition of monocarboxylate transporter-1 (MCT1) by AZD3965 enhances radiosensitivity by reducing lactate transport. Mol Cancer Ther 2014;13:2805-16.

78. Zhao Z, Wu MS, Zou C, et al. Downregulation of MCT1 inhibits tumor growth, metastasis and enhances chemotherapeutic efficacy in osteosarcoma through regulation of the NFkappaB pathway. Cancer Lett 2014;342:150-8.

79. De Saedeleer CJ, Porporato PE, Copetti T, et al. Glucose deprivation increases monocarboxylate transporter 1 (MCT1) expression and MCT1-dependent tumor cell migration. Oncogene 2014;33:4060-8.

80. Izumi H, Takahashi M, Uramoto $H$, et al. Monocarboxylate transporters 1 and 4 are involved in the invasion activity of human lung cancer cells. Cancer Sci 2011;102:1007-13. 